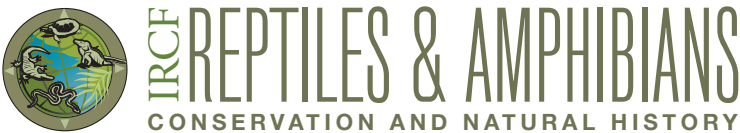

\section{Glimpses of Social Behavior in Grenada Bank Treeboas (Corallus grenadensis)}

Robert W. Henderson ${ }^{1}$, Billie Harrison ${ }^{2}$, Craig S. Berg ${ }^{2}$, and E. Marie Rush ${ }^{3}$

1'Milwaukee Public Museum, Milwaukee, Wisconsin 53233, USA (henderson@mpm.edu)

${ }^{2}$ Milwaukee County Zoo, Milwaukee, Wisconsin 53226, USA

${ }^{3}$ St. George’s University, St. George’s, Grenada, West Indies

illingham (1987) noted that "Social behavior in snakes Itends to center around their reproductive activities." Nine species comprising the Neotropical boid genus Corallus have a collective range that extends from Guatemala to southeastern Brazil, and despite several species being relatively common in appropriate habitat, observations of social behavior in the field are almost nonexistent. Only recently has mating (but no courtship) been observed in C. annulatus in Colombia (Muñoz et al. 2013) and C. hortulanus in Brazil (da Costa Silva and Henderson 2014).
On 9 June 2015 (moon in its third quarter; wet season with rain earlier in the day) at a site in central Grenada, we observed what we consider courtship in the Grenada Bank Treeboa (C. grenadensis). In a cemetery at $2100 \mathrm{~h}$ we observed a large (1,470 mm SVL as of 23 January 2015) female resting on the branch of a Candle Bush Tree (Senna alata) and close to the top rail of a chain-link fence bordering the cemetery (Fig. 1). The following observations were made with intermittent white light and more prolonged observations with illumination through a red filter.

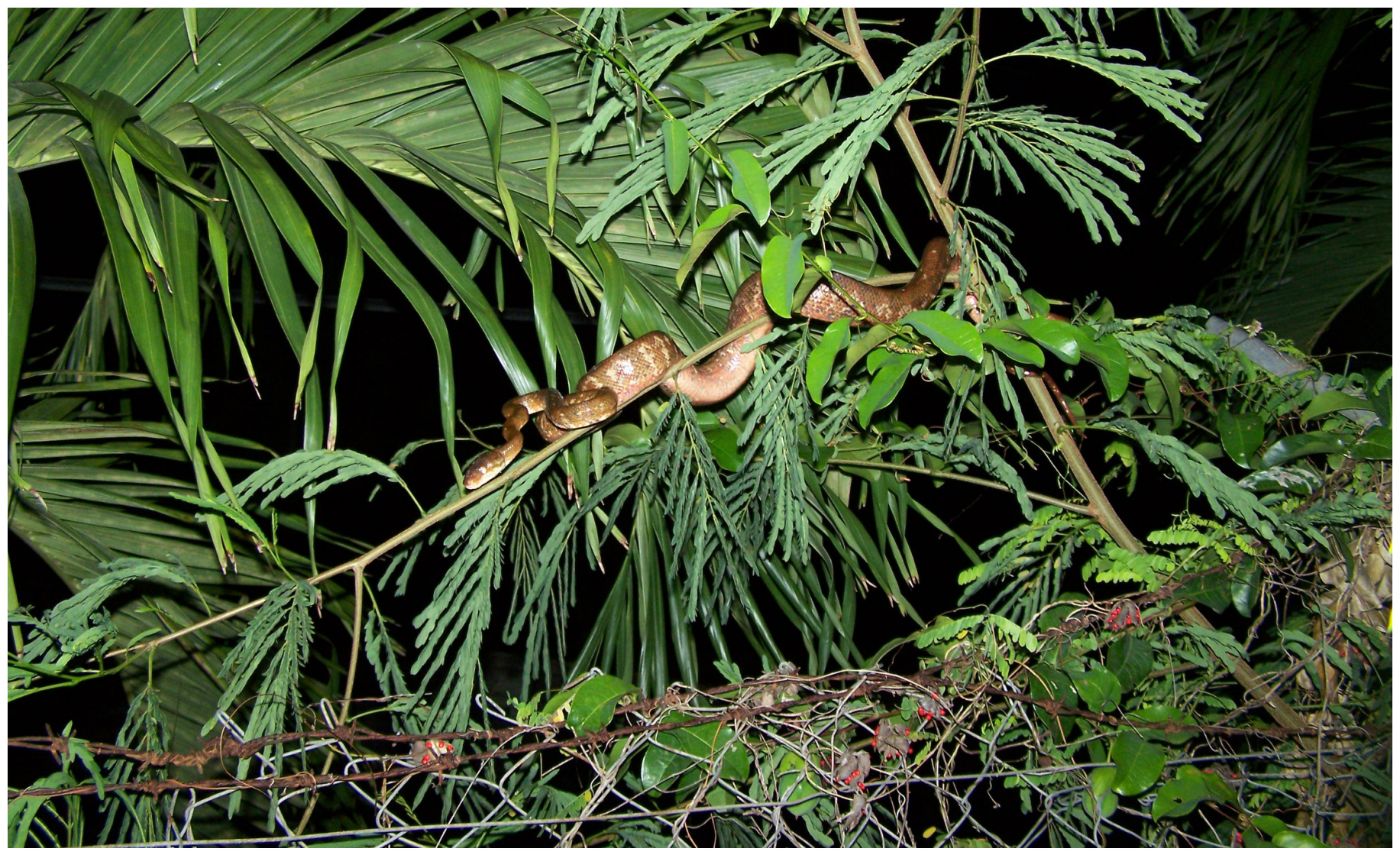

Fig. 1. A female Grenada Bank Treeboa (Corallus grenadensis). Photograph by Craig S. Berg. 


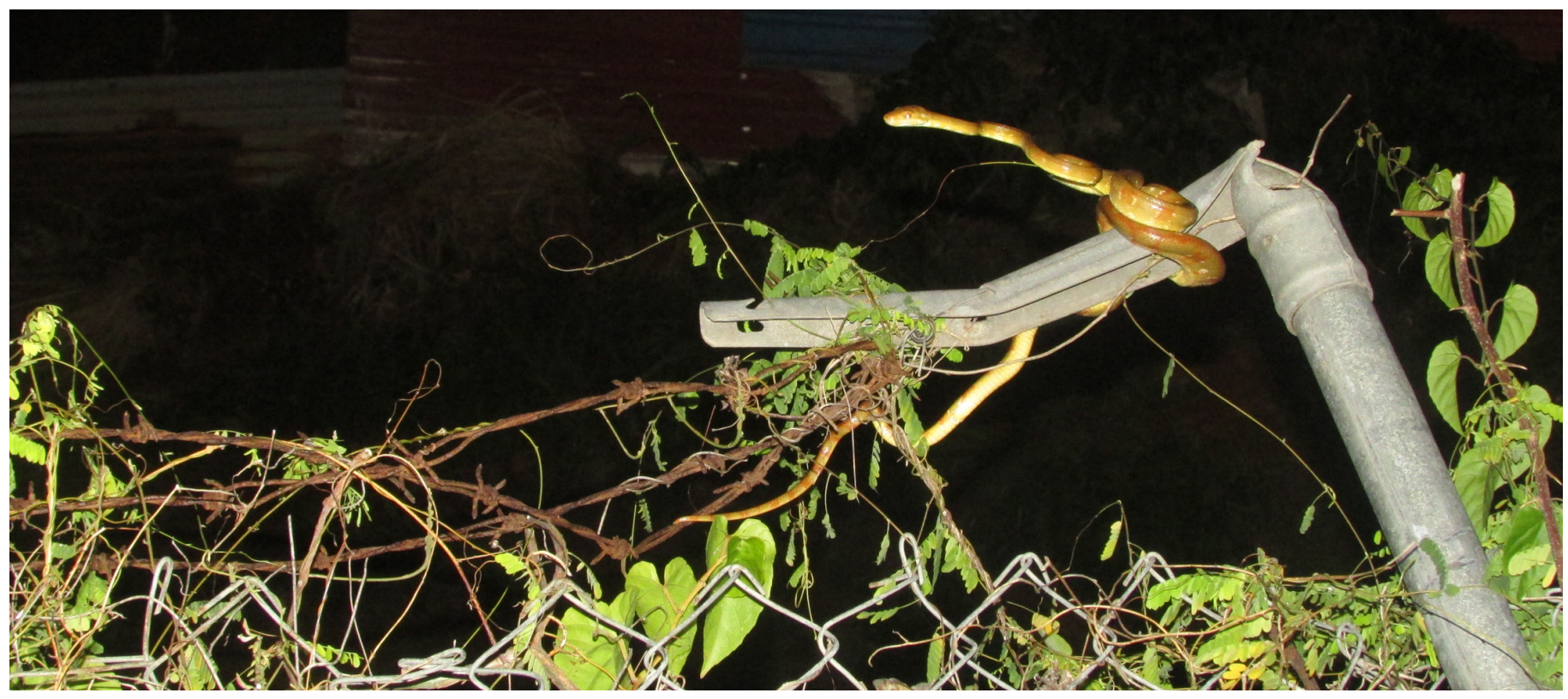

Fig. 2. An unsexed Grenada Bank Treeboa (Corallus grenadensis) along the same fence line as the female in Fig. 1. Photograph by Robert W. Henderson.

At $2103 \mathrm{~h}$, we saw an adult male $(-1,250 \mathrm{~mm} \mathrm{SVL})$ crawling rapidly into a hollow in the trunk of a Bayleaf Tree (Pimenta dioica). At $2105 \mathrm{~h}$, a smaller adult (unsexed) was coiled on the upper rail of the same fence and about $7 \mathrm{~m}$ from the female (Fig. 2). At about 2107, despite the presence of three persons with headlamps standing within $2-5 \mathrm{~m}$, the male emerged from the tree hollow (Fig. 3) and moved down to the chain link fence and into the proximity of the female (Fig. 4). With very slow and intermittent advances, the male approached the female and by $2120 \mathrm{~h}$ they were in contact. The male displayed frequent tongue-flicks to the female's body, but at $2150 \mathrm{~h}$ their heads were facing away from one another and their tails were not close (Fig. 5). At 2215 h, the male had his tail wrapped around the female's mid-section and their heads were in virtual contact. At $2221 \mathrm{~h}$, we were forced to terminate observations and quickly sexed the two snakes. At $2225 \mathrm{~h}$, the male had retreated into the hollow of the Bayleaf Tree but the female remained on the fence. These observed behaviors (frequent tongue-flicks, dorsal body looping, dorsal advance, and possible chin rubbing) are elements of "tactile-chase," the initial phase of courtship (Gillingham 1987; Tolson 1992; Tolson and Henderson 1993). We suspect that the male may have been making advances toward the female when we arrived at the fence and saw him retreat into the tree hollow. We also suspect that he likely resumed his advances after we departed the cemetery.

This same female had previously been observed by EMR on the same fence (25 February 2012) and also in a nearby Mango Tree (23 January 2015). Although we have only scant movement data for $C$. grenadensis, marked individuals have been found in close proximity $(<20 \mathrm{~m})$ to previous captures after intervals of more than one year (Henderson 2015). That

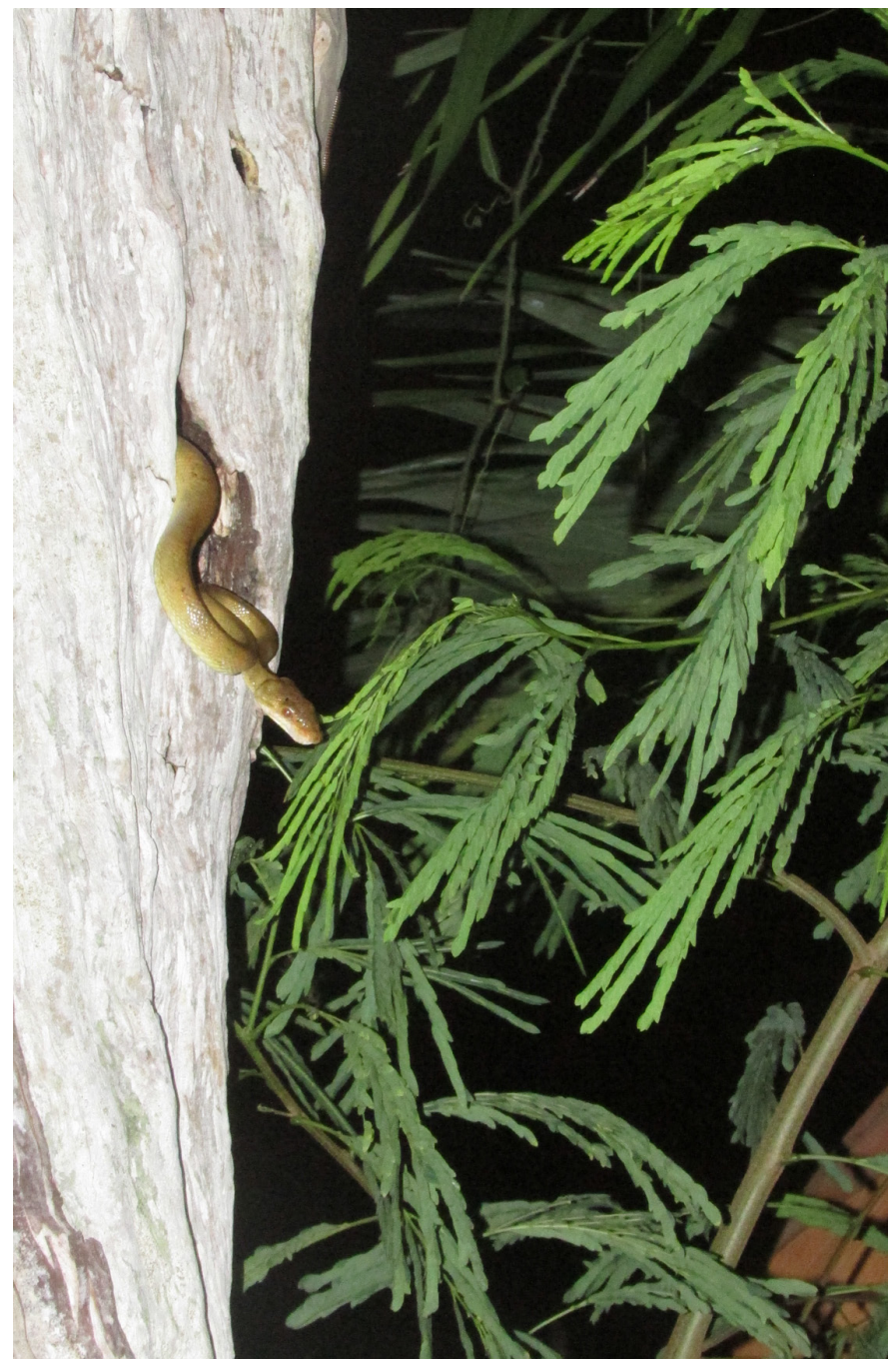

Fig. 3. A male Grenada Bank Treeboa (Corallus grenadensis) emerging from a tree cavity. Photograph by Robert W. Henderson. 


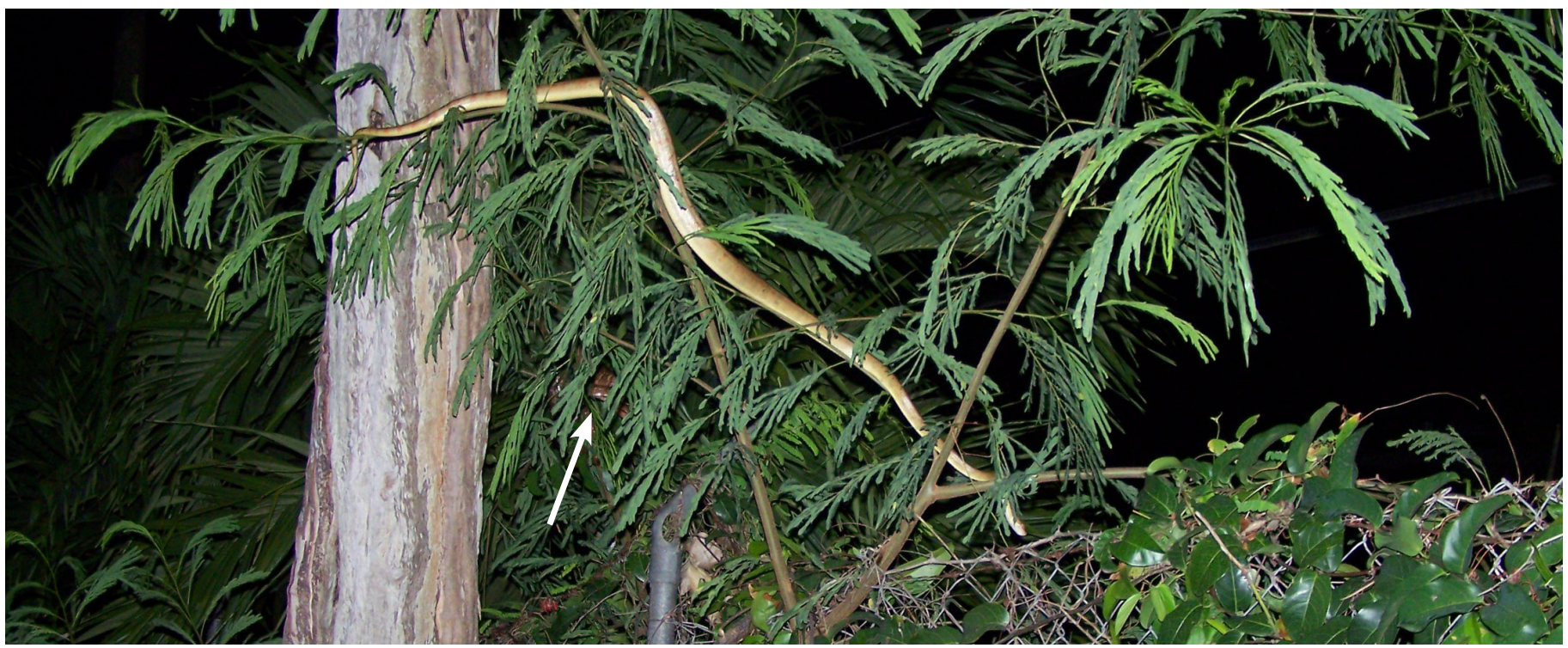

Fig. 4. The male Grenada Bank Treeboa (Corallus grenadensis) from Fig. 3 descending to the fence and the nearby female (arrow). Photograph by Craig S. Berg.

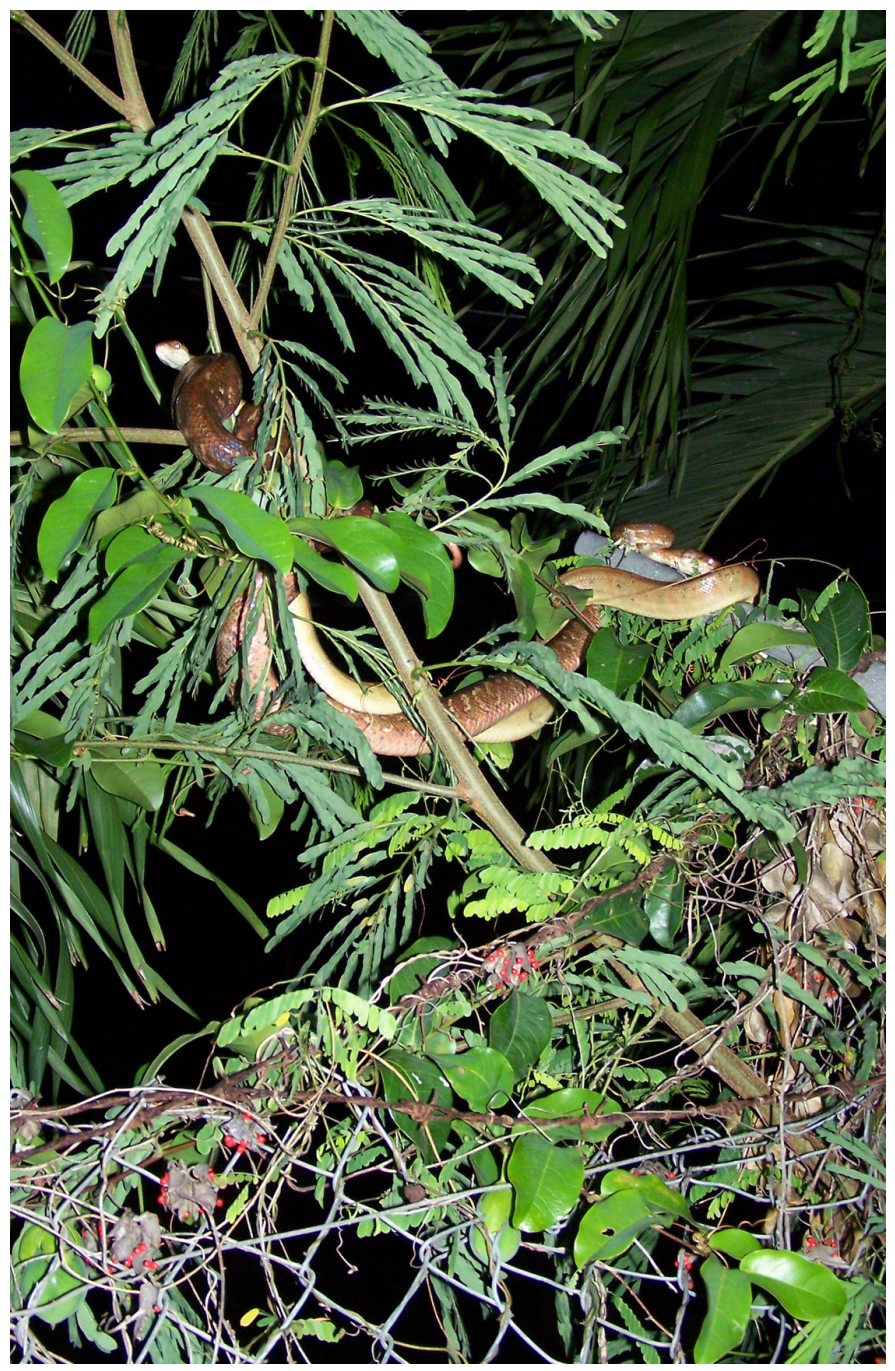

Fig. 5. Male and female Grenada Bank Treeboas (Corallus grenadensis) entwined atop the chain-link fence. Photograph by Craig S. Berg. this female was still living in the cemetery is therefore not surprising, especially considering the virtual absence of human activity in the cemetery after dark.

Earlier (1920 h) on the same night (9 June), we observed one large boa $(\sim 1,100 \mathrm{~mm} \mathrm{SVL})$ and two smaller boas at about $8.0 \mathrm{~m}$ above ground on a branch of a Golden Apple Tree (Spondias cytherea). Because we were about six meters below the snakes, we were unable to observe positioning of tails relative to one another. We assume the conspicuously larger boa was a female and the two smaller individuals were males. When first observed, the largest and one of the smaller boas were in physical contact. Each was anchored by its tail to separate branches, but a portion of the smaller snake's body can be seen beneath the larger animal (Fig. 6). Whether or not copulation was occurring would be another guess, but that seems unlikely. The third boa descended along the branch holding the other two, and eventually made contact. At 2246 h, we returned to the tree in which we saw the trio, but only one boa was observed.

Elements of the behavior observed between the snakes on the fence parallel some of those observed in a mating pair of the closely related (Colston et al. 2013) C. hortulanus (da Costa Silva and Henderson 2014). Although courtship was not witnessed in the $C$. hortulanus, at times during copulation the boas were facing in opposite directions and at others the male rubbed his head on the female's neck. Although we did not observe neck-rubbing in $C$. grenadensis, at one point the male's head was above and in contact with that of the female.

Previous observations that we consider "social" occurred on 20-25 April 1993 (moon a waning crescent to new; dry season) at Westerhall Estate in southern Grenada when, on five successive nights, groups of three or four adult C. grenadensis were observed in either a Mango or a Nutmeg tree. 


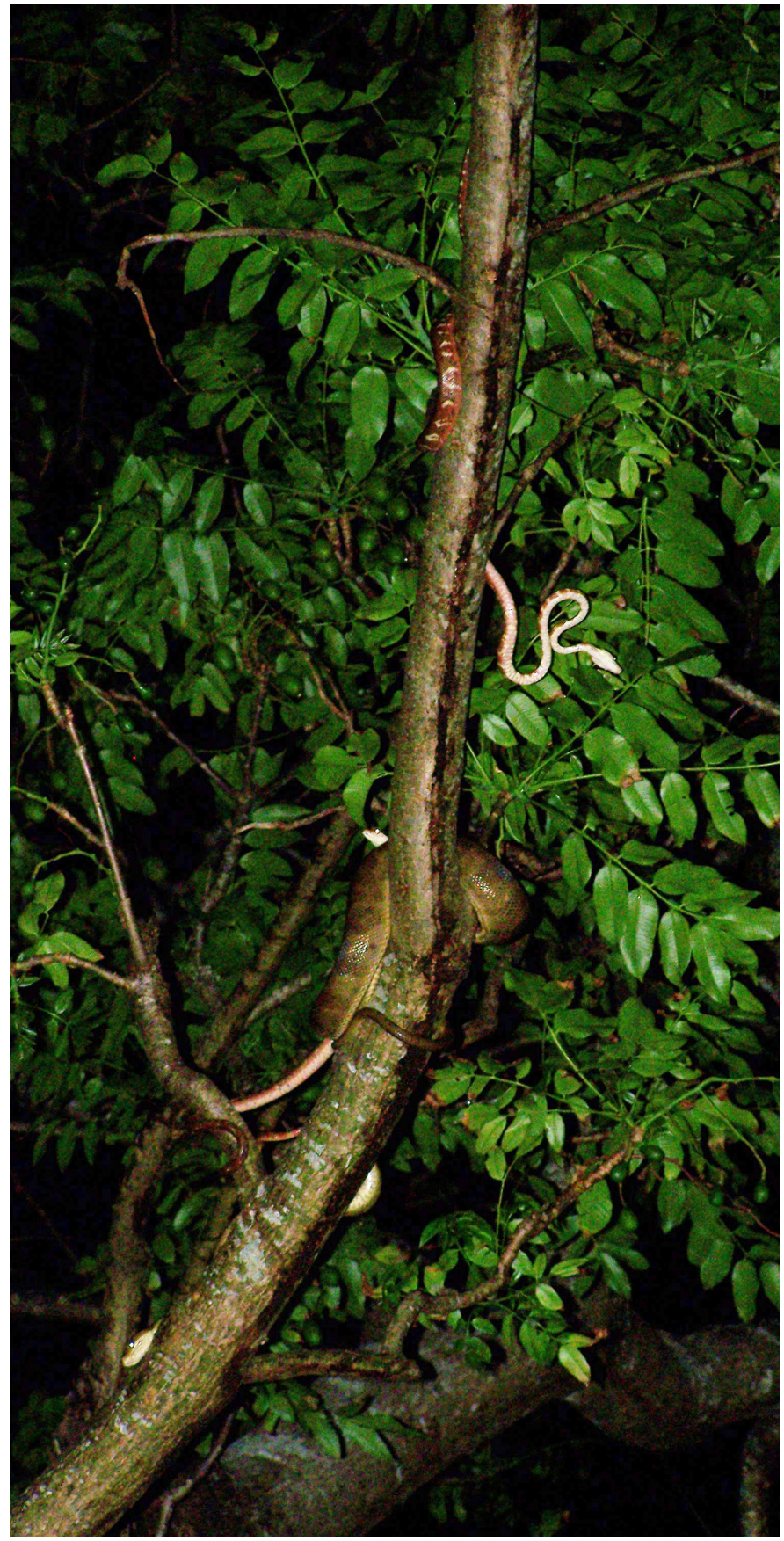

Fig. 6. Three Grenada Bank Treeboas (Corallus grenadensis) sharing the same branch. The centrally located boa is the largest and presumably is a female. Photograph by Craig S. Berg.
The boas were always in very close proximity $(<1.0 \mathrm{~m})$, and on two of those nights three boas were in contact. Although at least one of the boas was a male, we were unable to capture and sex the others (Henderson 2015).

In addition to our June observations of social behavior, we encountered C. grenadensis that were smaller $(<400 \mathrm{~mm}$ SVL) than any we had previously observed in June. These close-to-neonate-sized boas came from elevations ranging from near sea level in the Grenadines to about $530 \mathrm{~m}$ above sea level at Grand Etang National Park on Grenada. These recent observations seem to indicate wider windows for time of mating and parturition than previously estimated.

\section{Acknowledgments}

We thank Isadore Monah for his kind hospitality. The Windway Foundation provided funding for Henderson's participation in the fieldwork and the Milwaukee Public Museum provided logistical support. The efforts of Berg and Harrison were funded by the Zoological Society of Milwaukee County and the Milwaukee County Zoo. Isadore Monah and Christopher Tyrrell identified tree species for us. We thank the Ministry of Agriculture and the Department of Forestry on Grenada for their interest in our research and their continued support.

\section{Literature Cited}

Colston T.J., F.G. Grazziotin, D.B. Shepard, L.J. Vitt, G.R. Colli, R.W. Henderson, S.B. Hedges, S. Bonatto, H. Zaher, F.T. Burbrink. 2013. Molecular systematics and historical biogeography of tree boas (genus Corallus spp.). Molecular Phylogenetics and Evolution 66: 953-959.

da Costa Silva, P. and R.W. Henderson. 2014. Mating behavior of Amazon Treeboas, Corallus hortulanus (Squamata, Boidae), on Batatas Island, Piauí, Brazil. Herpetology Notes 7: 335-336.

Gillingham, J.C. 1987. Social behavior, pp. 184-209. In: R.A. Seigel, J.T. Collins, and S.S. Novak (eds.), Snakes: Ecology and Evolutionary Biology. Macmillan Publishing Co., New York, NY.

Henderson, R.W. 2015. Natural History of Neotropical Treeboas (genus Corallus). Edition Chimaira, Frankfurt am Main, Germany.

Muñoz, C.A., R.W. Henderson, and J.M. Daza. 2013. First observations in the wild of mating in the arboreal boid, Corallus annulatus. Herpetology Notes 6: 537-539.

Tolson, P.J. 1992. The reproductive biology of the Neotropical boid genus Epicrates (Serpentes: Boidae), pp. 165-178. In: W.C. Hamlett (ed.), Reproductive Biology of South American Vertebrates. Springer-Verlag, New York.

Tolson, P.J. and R.W. Henderson. 1993. The Natural History of West Indian Boas. R\&A Publishing Ltd., Taunton, England. 